\title{
Diversidade de Simuliidae (Diptera: Nematocera) de três cursos d' água no parque ecológico da Klabin S.A. - Telêmaco Borba, Estado do Paraná
}

\author{
Simuliidae diversity (Diptera: Nematocera) of three water \\ courses in Klabin's ecological park - Telêmaco Borba, State \\ of Paraná
}

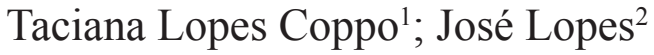

\section{Resumo}

Os simulídeos têm sido objeto de preocupação devido ao seu hábito hematófago, forte antropofilia e alta proliferação, causando desconforto à população, prejuízos em atividades agropecuárias e de turismo rural, além de serem vetores de patógenos. Objetivando conhecer a estrutura de comunidade e diversidade específica desses insetos, foi realizado o levantamento de espécies em três riachos de um parque ecológico em Telêmaco Borba - Paraná. Coletaram-se imaturos em substratos minerais e vegetais no leito dos rios. Efetuaram-se análises físicas e químicas da água. Foram coletados 14397 indivíduos, sendo 14150 larvas e 247 pupas de simulídeos. Identificaram-se as espécies Simullium subnigrum, S. subpallidum, S. rubrithorax, S. incrustatum, S. pertinax, S. inaequale, S. anamariae, S. rubiginosum, $S$. travassosi, $S$. riograndense e $S$. dinelli. Este é o primeiro registro de $S$. rubiginosum e $S$. dinelli para o Estado do Paraná. As áreas de menor impacto apresentaram maior diversidade, entretanto áreas impactadas apresentaram maior abundância de borrachudos, representados por apenas uma espécie, $S$. rubrithorax. Conclui-se que áreas de preservação com ribeirões de águas lóticas e mata ciliar preservada constituem-se como área de refúgio para as espécies de simulídeos. Ambientes antropofizados interferem na dinâmica das espécies, privilegiando uma ou mais, que tornam-se abundantes e dominantes do criadouro.

Palavras-chave: Borrachudos. Larvas. Criadouro. Diversidade.

\begin{abstract}
Simuliidae have been considered object of concern due to their hemophagia, anthropophilic habits and high proliferation, causing discomfort to the population, damages to agricultural activities and rural tourism, besides being pathogens vectors. With the purpose of understanding the community structure and specific diversity of these insects, a survey of the species was conducted in three streams in an ecological park in Telêmaco Borba - Paraná, Brazil. Immature specimens were collected in mineral and vegetable substrates on the riverbanks. Chemical and physical analyses of the water were carried out. The Simuliidae collection included 14,397 individuals, being 14,150 larvae and 247 pupae. The following species were identified: Simullium subnigrum, S. subpallidum, S. rubrithorax, S. incrustatum, S. pertinax, $S$. inaequale, $S$. anamariae, S. rubiginosum, $S$. travassosi, $S$. riograndense and $S$. dinelli.
\end{abstract}

\footnotetext{
${ }^{1}$ Bacharel em Ciências Biológicas pela Universidade Estadual de Londrina (UEL); Mestranda do curso de pós-graduação em Ciências Biológicas da Universidade Estadual de Londrina (UEL). Londrina - PR. E-mail: taci_lc@yahoo.com.br

${ }^{2}$ Departamento de Biologia Animal e Vegetal (UEL). E-mail: jea@uel.br
} 
This is the first registry of $S$. rubiginosum and $S$. dinelli in the State of Paraná. The lesser-impacted areas presented greater diversity. However, the impacted areas presented an abundance of borrachudos, represented by a single species, S. rubrithorax. It was concluded that preservation areas with lotic waters and riparian forest are considered a refuge area for Simuliidae species. Impact of anthropical activities upon the environment interferes in the dynamics of species, favoring one or more of them, which proliferate and predominate.

Key-words: Black flies. Larvae. Breeding site. Diversity.

\section{Introdução}

Representantes da família Simuliidae, conhecidos popularmente como "borrachudos" ou "pinus", são dípteros com distribuição mundial, não sendo encontrados apenas na região Antártica, nos desertos e em ilhas desprovidas de córregos (CROSSKEY, 1990).

Atualmente, são conhecidas 1.720 espécies de simulídeos no mundo, dos quais 355 estão assinaladas para a região Neotropical e 83 espécies são encontradas no Brasil, as quais pertencem a duas tribos, Prosimuliini e Simuliini, e 90\% das espécies são do gênero Simulium Latreille, 1802 (CUNHA, 2001; STRIEDER, 2004).

O hábito hematófago das fêmeas coloca os simulídeos em evidência na medicina humana e veterinária, uma vez que interferem na qualidade de vida das pessoas e na produtividade animal. Suas picadas, além de causarem desconforto, podem levar a reações alérgicas e serem veículos de transmissão de alguns patógenos. Causam ainda prejuízos ao turismo e à economia, principalmente na agropecuária, levando à perda de peso e diminuição de leite em bovinos, e até à morte em aves (CUNHA, 2001).

$\mathrm{O}$ alto teor de oxigênio da água é condição essencial para o desenvolvimento das larvas de borrachudos, devido a sua necessidade metabólica. Assim, apresentam preferência por áreas de maior correnteza dos rios para a postura. Os imaturos são relativamente tolerantes à presença de grande quantidade de matéria orgânica e também às variações de $\mathrm{pH}$, salinidade e condutividade da água, sendo intolerantes, na maioria dos casos, à poluição
(STRIEDER; SANTOS; PÊS, 2002; STRIEDER; SANTOS; VIEIRA, 2006).

A distribuição e a abundância das espécies podem ser influenciadas ainda pela vazão dos cursos de água, disponibilidade de substratos para a fixação das formas imaturas, composição da vegetação ciliar, assim como, pelas ações do homem nas áreas limítrofes (CROSSKEY, 1990; STRIEDER; SANTOS; PÊS, 2002; SANTOS-JUNIOR et al., 2007).

No Brasil, segundo Santos (2008), as principais pesquisas com Simuliidae concentram-se na Região Amazônica, nos estados de São Paulo e Rio Grande do Sul. As informações em relação à fauna de Simuliidae no Estado do Paraná são escassas. Registram-se os trabalhos de Dellome Filho (1991) no rio Marumbi e Cunha e Bassi (1997) no rio São João, ambos na região litorânea do Estado, onde foram encontradas doze espécies de borrachudos.

Para o primeiro planalto paranaense, constatamse os trabalhos realizados por Lozovei, Cunha e Bassi (1989), no rio Dom Rodrigo, Cunha, Coscarón e Bassi (1998), no rio Cachoeirinha, Lozovei et al. (2004) e Petry (2005), ambos estudos realizados em Almirante Tamandaré - PR.

No terceiro planalto paranaense, Santos (2008), em um trabalho pioneiro realizado em ribeirões do municipio de Londrina, PR, registrou para o Norte do estado, 17 espécies de simulídeos, totalizando 24 espécies registradas para a região.

Dada a escassez de estudos relacionados a simulídeos no Estado do Paraná, foi realizado o estudo da diversidade, abundância e estrutura da comunidade de imaturos de Simuliidae em três 
ribeirões no Parque Ecológico da empresa Klabin em Telêmaco Borba - Paraná.

\section{Material e métodos}

\section{Área de estudo}

O trabalho foi realizado na Fazenda Monte Alegre, dentro do parque ecológico de propriedade da empresa Klabin S.A. de papel e celulose (Figura 1). A fazenda possui 126.373,10 ha e está localizada nas coordenadas geográficas $24^{\circ} 12^{\prime} 42^{\prime}$ S e 50³3'26”W, no município de Telêmaco Borba - PR. O parque possui uma área de 11196 ha (BENNEMANN, 2008).

A área apresenta altitude média de $885 \mathrm{~m}$ e o clima, segundo a classificação de Köppen, enquadrase como subtropical, com temperatura média do mês mais frio de $16,3^{\circ} \mathrm{C}$ e temperatura média do mês mais quente $23,2^{\circ} \mathrm{C}$. A precipitação pluviométrica média anual é de 1478 mm (REIS et al., 2006).

$\mathrm{Na}$ paisagem local, ocorrem três tipos de formações vegetacionais: Floresta Estacional Semidecidual, Floresta Ombrofila Mista e pequenas manchas de Campos Naturais. O sub-bosque é dominado por samambaias, bromélias, cipós e avencas (REIS et al., 2006; BENNEMANN, 2008).

Os pontos onde foram realizadas as coletas apresentavam as seguintes características:

Ponto 1. Arroio Cascatinha, área de cachoeira com dossel fechado e vegetação ciliar conservada, pouca incidência solar. Leito essencialmente composto por rochas.

Ponto 2. Arroio Cascatinha, ponto imediatamente acima da cachoeira, dossel fechado e vegetação ciliar conservada, pouca incidência solar. O leito inicialmente composto por areia e depois rochas, sem queda d'água.

- Ponto 3. As coletas foram realizadas no ribeirão João Pinheiro, em trecho com leito rochoso e correnteza forte em sentido a uma cachoeira. Área com dossel fechado e vegetação ciliar conservada, pouca incidência solar. Precede este ponto área de fisionomia lêntica, em um leito essencialmente arenoso.

- Ponto 4. Coletas também realizadas no ribeirão João Pinheiro, área de cachoeira com dossel fechado e vegetação ciliar conservada, baixa incidência solar. Área de correnteza, leito rochoso (Figura 2).

- Ponto 5. Canal da barragem ("ribeirão da Barragem"). Este ponto se localiza imediatamente após a lagoa artificial formada pela barragem do ribeirão João Pinheiro. A vazão da lagoa dá-se por canal artificial, construído a partir de concreto e rochas basálticas. Água com velocidade alta, indo diretamente para área mais baixa e formando uma queda de água de aproximadamente $20 \mathrm{~cm}$. A vegetação ciliar é praticamente ausente, portanto com alta incidência solar (Figura 3).

Ponto 6. Ponto localizado também no "Ribeiro da Barragem", em trecho à frente da área artificial. Trata-se de uma área de dossel fechado e vegetação conservada. O leito apresenta tanto pontos rochosos quanto pontos de areia, a velocidade da água em geral é baixa, aumentando apenas em locais onde há rochas no leito. 


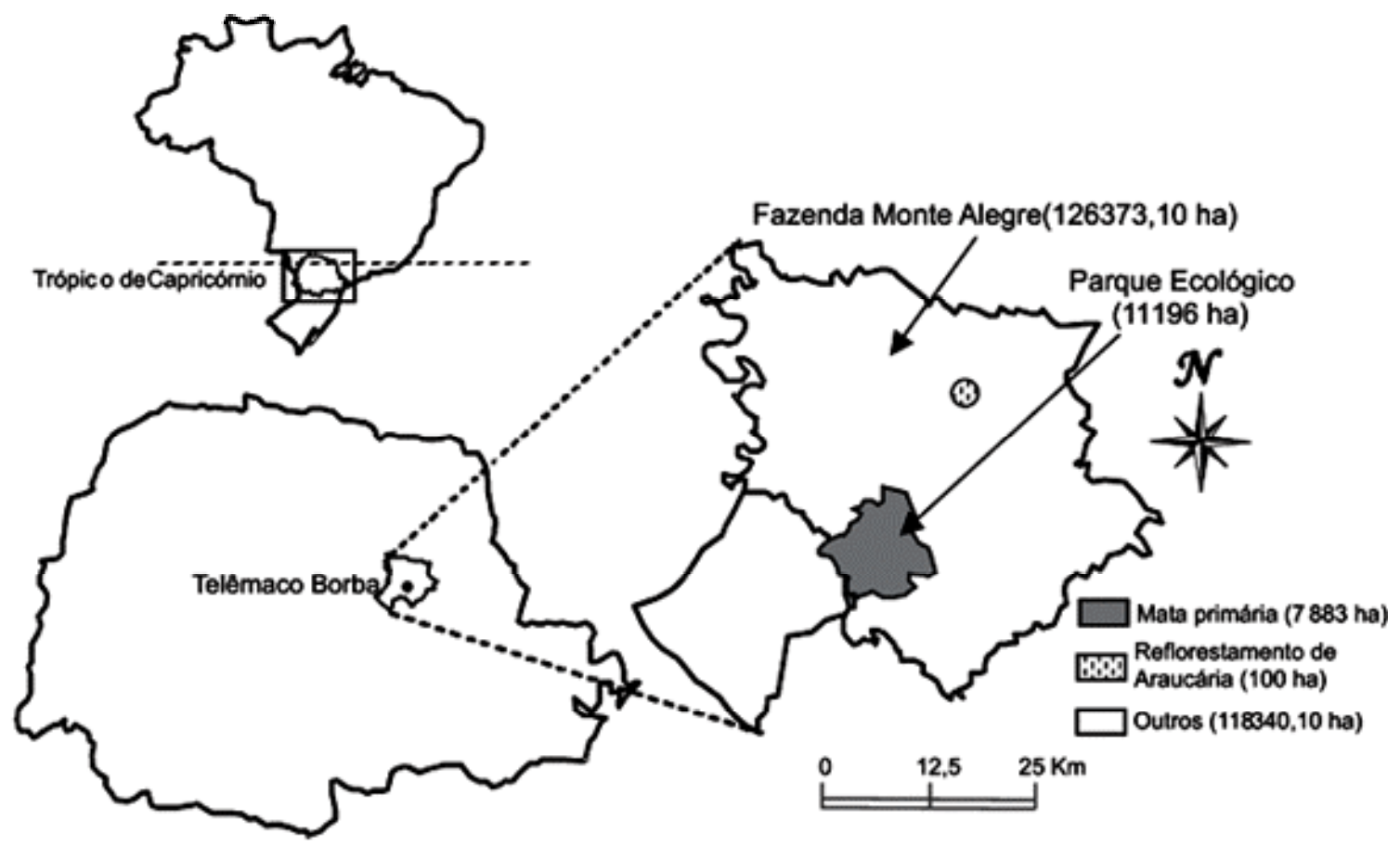

Figura 1. Localização do município de Telêmaco Borba, da Fazenda Monte Alegre e do Parque ecológico da Klabin (Fonte: Reis et al., 2006).

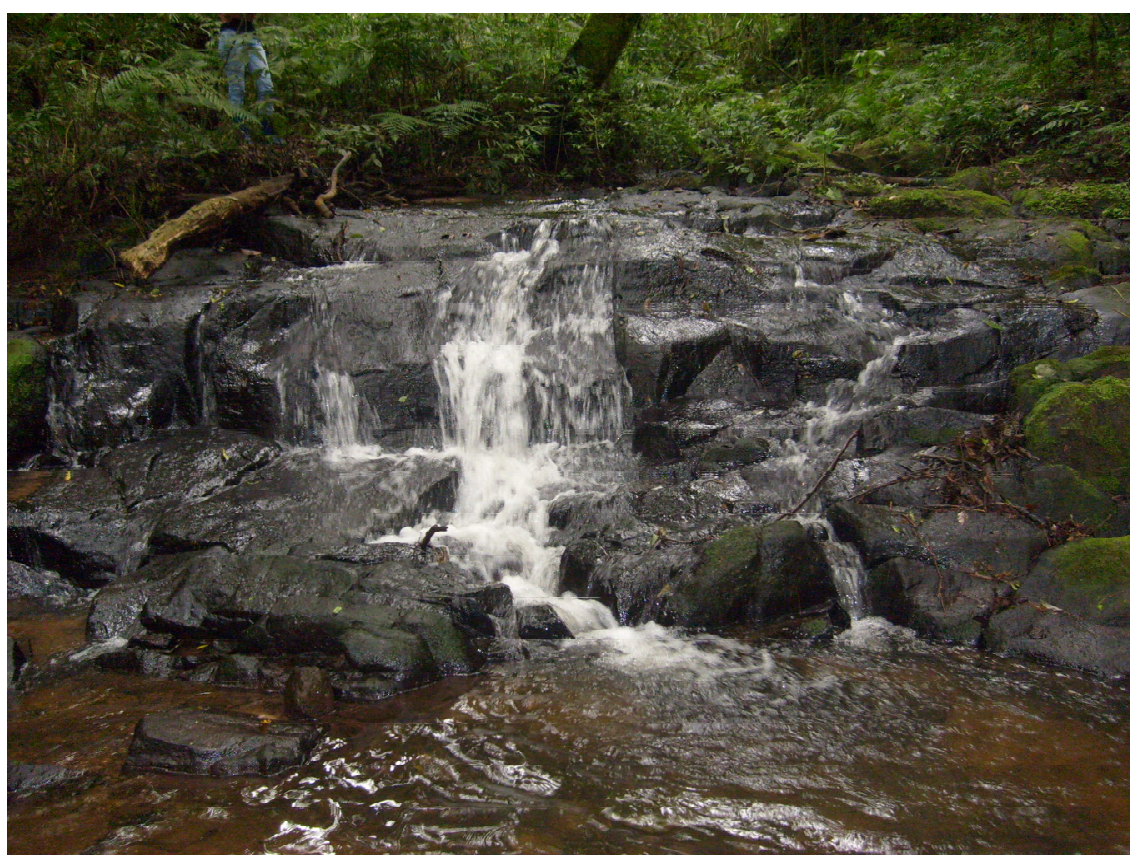

Figura 2. Ponto de coleta 4, no ribeirão João Pinheiro, Parque ecológico da Klabin - Telêmaco Borba,Paraná. Março, 2008. 


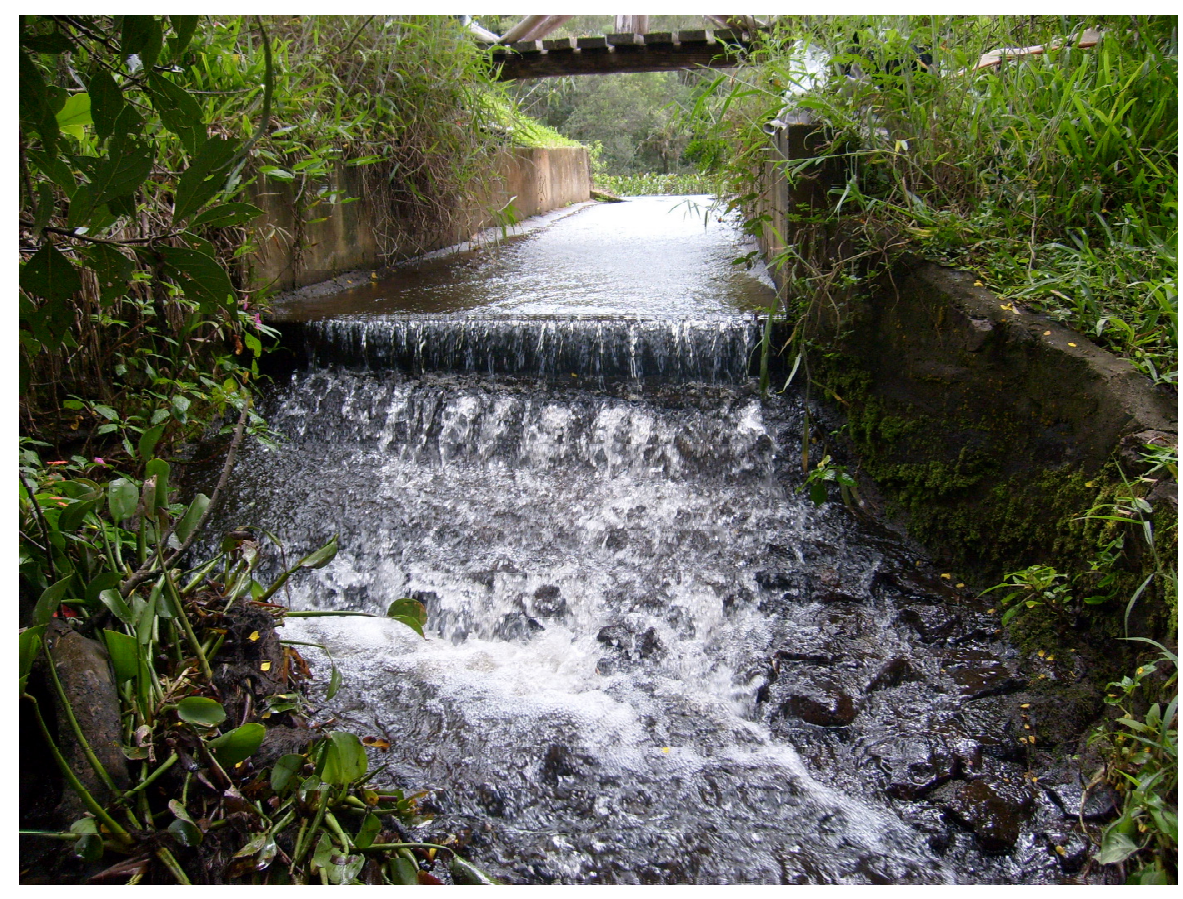

Figura 3. Ponto de coleta 5, no ribeirão da Barragem, Parque ecológico da Klabin - Telêmaco Borba, Paraná. Março, 2008.

\section{Metodologia de coletas}

Em março de 2008, foram coletados imaturos (larvas e pupas) de simulídeos em três ribeirões do parque ecológico da Klabin, com duração de quatro horas em cada local. Cada riacho foi amostrado em dois pontos distintos. Em cada ponto as coletas foram realizadas em diferentes substratos, sendo: diretamente no leito rochoso; na vegetação marginal pendente na linha de água ou submersa e em folhas soltas no fundo do leito.

Para as coletas no leito rochoso, foi utilizado um amostrador do tipo Surber com área amostral de 900 $\mathrm{cm}^{2}$ e malha de $500 \mu \mathrm{m}$. No momento da coleta, o amostrador foi posicionado contra a correnteza, e o substrato rochoso, dentro da área amostral, foi esfregado com auxílio de uma bucha vegetal, a fim de que os imaturos fossem direcionados para o amostrador.

Os imaturos foram transferidos para sacos plásticos (40X60X0,18cm), contendo álcool a 90\%.
Na triagem em laboratório, para amostras com muito sedimento, foi utilizado o método da flutuação, que consistiu na adição de solução supersaturada de açúcar $(250 \mathrm{~g} / \mathrm{L}$ de água) à amostra, a fim de que as larvas e pupas, menos densas que a solução, flutuassem facilitando a triagem (SILVERA et al. apud SANTOS, 2008).

As coletas em vegetação marginal foram realizadas com a retirada da vegetação marginal em contato com a água, em espaço de $50 \mathrm{~cm}$. As folhas soltas foram retiradas diretamente do leito. O material coletado, nos dois procedimentos, foi colocado em recipientes de transporte e conservados em álcool a 90\%.

Foram realizadas também medidas físicas e químicas da água nos pontos estudados (largura, profundidade, $\mathrm{pH}$,oxigêniodissolvido, condutividade e temperatura). As análises químicas da água foram feitas através do medidor multiparamétrico portátil. 
Para o cálculo da velocidade da água, em cada área foi selecionado um trecho de $10 \mathrm{~m}$, onde foram realizadas dez medidas de largura com o uso de uma trena e dez séries de profundidade, com o uso de um bastão métrico. Em seguida, uma bola de tênis de mesa, previamente preenchida com $25 \mathrm{~mL}$ de água era solta no marco zero e o tempo gasto para a sua chegada ao ponto final $(10 \mathrm{~m})$ era cronometrado. $\mathrm{O}$ número de repetições variou de acordo com a largura dos ribeirões. De posse dessas medidas calculou-se a vazão, segundo a fórmula:

\section{$\mathrm{Q}=\underline{\mathrm{Lm} \times \mathrm{Pm} \times \mathrm{C} \times 0,85}$ $\operatorname{Tm}$}

Onde $\mathrm{Q}=$ Vazão; $\mathrm{C}=$ comprimento do trecho; $\mathrm{Lm}=$ largura média do trecho; $\mathrm{PM}=$ profundidade média; $\mathrm{Tm}=$ tempo médio; $0,85=$ constante aplicada para corrigir o atrito da água com o fundo (PORTO ALEGRE, 2006).

Após o processo de triagem, apenas as larvas de último ínstar com histoblasto branquial formado e as pupas foram utilizadas para a identificação das espécies. As identificações foram realizadas através de chaves dicotômicas de Coscarón e Wygodzinsky (1984); Coscarón (1991) e Strieder, Corseuil e PyDaniel (1992).

A fim de analisar a diversidade e estrutura da comunidade de cada área, foram calculados os padrões de variância e os índices de diversidade Simpson (D) e Shannon (H), e a este último foi aplicado o teste $\mathrm{t}$ para averiguar a existência de diferenças de diversidade na comunidade de simulídeos de cada ribeirão. A similaridade entre as áreas foi testada por meio do índice se similaridade de Sorensen.

\section{Resultados e discussão}

Foram coletados 14397 indivíduos, sendo 14150 larvas e 247 pupas de simulídeos. O ribeirão da Barragem foi o que apresentou a maior porcentagem de imaturos coletados $(87,7 \%)$, seguido pelo ribeirão João Pinheiro $(9,8 \%)$ e Arroio Cascatinha $(2,5 \%)$ (Tabela 1). Os dados físcos e químicos da água não se revelaram distintos entre os cursos de água (tabela 2).

Tabela 1 - Distribuição de imaturos coletados em diferentes substratos em três cursos de água da fazenda Monte Alegre, Parque Ecológico da Klabin, Telêmaco Borba - PR. Março de 2008

\begin{tabular}{lccccccccccc}
\hline $\begin{array}{l}\text { Cursos de } \\
\text { água }\end{array}$ & \multicolumn{3}{c}{ Cascatinha } & \multicolumn{3}{c}{ J. Pinheiro } & \multicolumn{2}{c}{ R. Barragem } & $\begin{array}{c}\text { Total } \\
\text { geral }\end{array}$ \\
\hline Substratos & Larvas & Pupas & Total & Larvas & Pupas & Total & Larvas & Pupas & Total & \\
\hline Rochas & 204 & 11 & 215 & 861 & 10 & 871 & 11829 & 45 & 11874 & 12960 \\
Folhas & 84 & 18 & 102 & 48 & 1 & 49 & 342 & 116 & 458 & 609 \\
Vegetação & 24 & 15 & 39 & 478 & 17 & 495 & 280 & 14 & 294 & 828 \\
\hline Total & 312 & 44 & 356 & 1387 & 28 & 1415 & 12451 & 175 & 12626 & 14397 \\
\hline
\end{tabular}


Tabela 2 - Caracterização físico-química dos cursos de água da fazenda Monte Alegre, Parque Ecológico da Klabin, Telêmaco Borba - PR. Março de 2008

\begin{tabular}{|c|c|c|c|}
\hline & Cascatinha & J. Pinheiro & Barragem \\
\hline \multirow[t]{2}{*}{ Coordenadas } & $\mathrm{S} 24^{\circ} 46^{\prime} 59^{\prime \prime}$ & $\mathrm{S} 24^{\circ} 16^{\prime} 49,8^{\prime \prime}$ & $\mathrm{S} 24^{\circ} 16^{\prime} 59,7^{\prime \prime}$ \\
\hline & W $50^{\circ} 35^{\prime} 72^{\prime \prime}$ & W $50^{\circ} 34^{\prime} 56,5^{\prime \prime}$ & $\mathrm{W} 50^{\circ} 35^{\prime} 03^{\prime \prime}$ \\
\hline Altitude (m) & 750 & 751 & 750 \\
\hline Profundidade (cm) & $0,3-5$ & $3-5$ & $3-6$ \\
\hline Largura (m) & $0,25-1$ & $0,32-2,5$ & $1,14-1,57$ \\
\hline Temperatura da água $\left({ }^{\circ} \mathrm{C}\right)$ & 21 & 21,5 & 21 \\
\hline Velocidade $\mathbf{m} / \mathbf{s}$ & 2,4 & 2,2 & 2,0 \\
\hline Vasão (m3/s) & 0,081 & 1,62 & 1,6 \\
\hline pH & 5,32 & 5,32 & 5,4 \\
\hline Condutividade $(\mu \mathrm{S} / \mathrm{cm})$ & 21 & 32 & 26 \\
\hline O2 Dissolvido (\%) & 6,5 & 7,44 & 6,84 \\
\hline Dossel & Fechado & Fechado & Aberto \\
\hline Vegetação ripária & Presente/média & Presente/ pouca & Ausente \\
\hline
\end{tabular}

Tabela 3 - Número de simulídeos coletados em diferentes cursos de água da fazenda Monte Alegre, Parque Ecológico da empresa Klabin, Telêmaco Borba - PR. Março/2008.

\begin{tabular}{lccccc}
\hline \multicolumn{1}{c}{ Curso de água } & $\begin{array}{c}\text { Ribeirão } \\
\text { Arroio } \\
\text { cascatinha }\end{array}$ & $\begin{array}{c}\text { RibeirãoJoão } \\
\text { Pinheiro }\end{array}$ & $\begin{array}{c}\text { Ribeirão da } \\
\text { Barragem }\end{array}$ & Total & \% \\
\hline Simulium subnigrum & 18 & 1 & 0 & 19 & 6,62 \\
S. subpallidum & 0 & 0 & 12 & 12 & 4,18 \\
S. rubrithorax & 0 & 0 & 105 & 105 & 36,59 \\
S. incrustatum & 17 & 10 & 5 & 32 & 11,15 \\
S. pertinax & 3 & 40 & 2 & 45 & 15,68 \\
S. inaequale & 5 & 2 & 28 & 35 & 12,20 \\
S. anamariae & 1 & 0 & 0 & 1 & 0,35 \\
S. rubiginosum & 1 & 0 & 25 & 26 & 9,06 \\
S. travassosi & 1 & 0 & 0 & 1 & 0,35 \\
S. riograndense & 0 & 7 & 0 & 7 & 2,44 \\
S. dinelli & 0 & 0 & 2 & 2 & 0,70 \\
S. subclavibranchium & 2 & 0 & 0 & 2 & 0,70 \\
\hline Indivíduos & 48 & 60 & 179 & 287 & 100 \\
Espécies & 8 & 5 & 7 & 12 & \\
Shannon (H) & 1,519 & 1,001 & 1,26 & - & \\
Simpson (D) & 0,7161 & 0,5128 & 0,6064 & - & \\
Variância & 0,018326 & 0,014652 & 0,0054484 & - & \\
\hline
\end{tabular}


Os maiores índices de diversidade tanto de Shannon quanto se Simpson foram obtidos para o arroio Cascatinha (oito espécies), seguido pelo ribeirão da Barragem (sete espécies) e ribeirão João Pinheiro (cinco espécies). Foram encontradas diferenças significativas de diversidade entre o arroio Cascatinha e o ribeirão João Pinheiro, segundo o teste $\mathrm{t}$ com $95 \%$ de confiança, sendo o primeiro mais diverso (Tabela 3).

Foram identificadas 12 espécies de borrachudos (tabela 3). Simulium anamariae, $S$. travassosi e $S$. subclavibranchium foram exclusivas do arroio Cascatinha; S. subpallidum, S. rubrithorax, Simulium (Ectemnaspis) dinelli (JOHAN, 1912), do ribeirão da Barragem; apenas S. riograndense do ribeirão João Pinheiro.

O resultado obtido na coleta realizada no ponto cinco (ribeirão da Barragem), uma área impactada, supera as áreas conservadas no que diz respeito à abundância, entretanto, quanto à riqueza, as áreas de menor impacto se mostraram mais representativas, fatos confirmados pelo índices de Shannon (Tabela 3). Esta correlação também foi observada por Strieder, Santos e Vieira (2006), em levantamento realizado em diferentes áreas no Rio Grande do Sul.

A presença de espécies exclusivas para alguns ribeirões, determina menor similaridade entre as áreas. O cálculo do índice de similaridade de Sorensen revelou que o arroio Cascatinha e o João Pinheiro apresentam 31\% de similaridade, o mesmo ocorrendo no arroio Cascatinha e no ribeirão da Barragem. Os ribeirões João Pinheiro e Barragem apresentaram apenas $25 \%$ de similaridade.

Verifica-se que as áreas menos impactadas foram mais semelhantes, diferenciando o ribeirão da Barragem pelo represamento e construção do escoadouro de concreto, que permitiu o estabelecimento de poucas espécies, porém com grande abundância (Figura 4). Peppinelli (2003) verificou a mesma situação ao realizar um levantamento em rios naturais e em rios com ação antrópica no Estado de São Paulo, neste último rio obteve poucas espécies, porém abundantes.

Comparando-se os três substratos de onde foram obtidos os imaturos, o mais abundante e de maior riqueza foi o estrato mineral (rocha), com 90\% dos indivíduos e nove espécies. Na vegetação marginal, obtiveram-se $5,75 \%$ dos indivíduos, com oito espécies; as folhas soltas perfizeram oito espécies representando 4,25\% do total de individuos (Figura 4).

A espécie mais abundante foi S. rubrithorax. Ela, assim como S. subpallidum foi encontrada tanto em substrato mineral quanto vegetal (Tabela 4), e isso ocorreu apenas no ribeirão da Barragem (Tabela 3), uma área de leito artificial de pequenas dimensões e grande alteração do rio, correnteza forte, dossel aberto e alta incidência solar. Segundo Coscarón (1991), S. rubrithorax apresenta preferência para cursos de água de correnteza forte, sobre substrato rochoso. S. subpallidum, segundo o mesmo autor, apresenta preferência por rios de baixa correnteza, entretanto Peppinelli (2003) coletou tal espécie em corpos de água de correnteza elevada. Resultados corroborados com o observado nesta pesquisa. A presença destas duas espécies, possivelmente, está relacionada às características físicas do local, uma vez que os componentes químicos da água não foram significativamente distintos entre os pontos, podendo sugerir um favorecimento de tais espécies, quando em situações artificiais. 


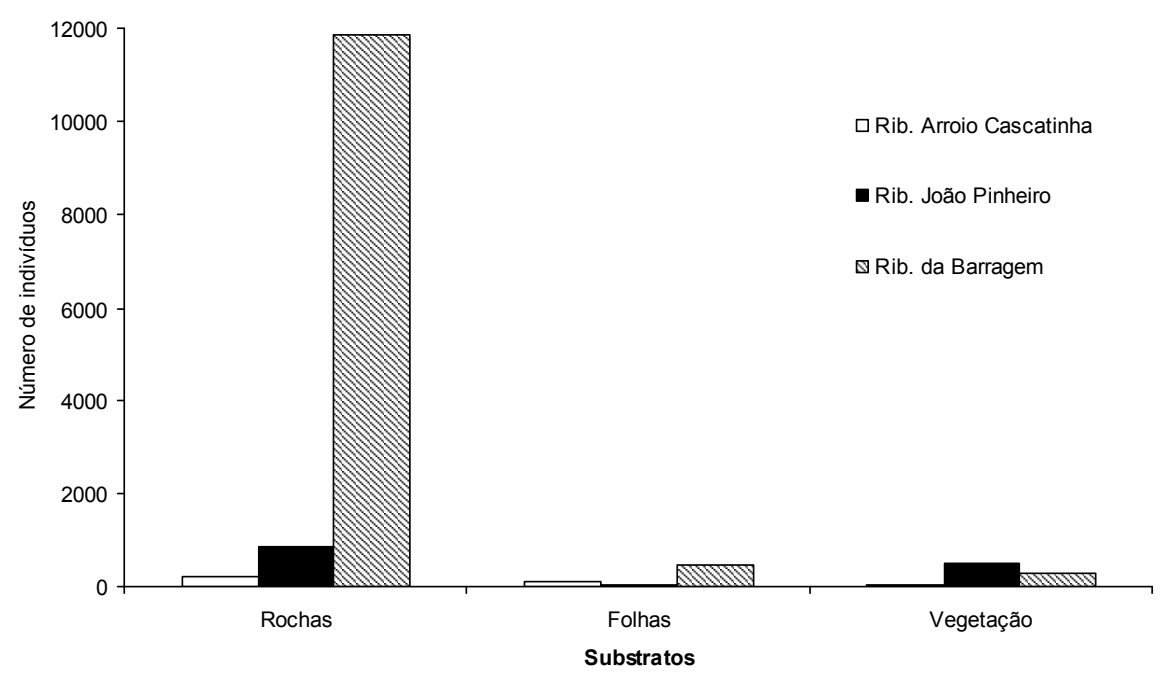

Figura 4 - Total de simulídeos coletados em diferentes subtratos em cursos de água do Parque Ecológico da Klabin, Telêmaco Borba - PR. Março de 2008.

Tabela 4 - Espécies de simulídeos coletadas em diferentes subtratos em cursos de água do Parque Ecológico da Klabin, Telêmaco Borba - PR. Março de 2008.

\begin{tabular}{lccccc}
\hline & Rochas & Folhas & Vegetação & Total & \% \\
\hline S. subnigrum & 7 & 5 & 7 & 19 & 6,62 \\
S. subpallidum & 10 & 1 & 1 & 12 & 4,18 \\
S. rubrithorax & 103 & 1 & 1 & 105 & 36,59 \\
S. incrustatum & 2 & 10 & 20 & 32 & 11,15 \\
S. pertinax & 3 & 6 & 36 & 45 & 15,68 \\
S. inaequale & 11 & 1 & 23 & 35 & 12,20 \\
S. anamariae & 1 & 0 & 0 & 1 & 0,35 \\
S. rubiginosum & 0 & 5 & 21 & 26 & 9,06 \\
S. travassosi & 0 & 1 & 0 & 1 & 0,35 \\
S. riograndense & 7 & 0 & 0 & 7 & 2,44 \\
S. dinelli & 0 & 0 & 2 & 2 & 0,70 \\
S. subclavibranchium & 2 & 0 & 0 & 2 & 0,70 \\
\hline Total & 146 & 30 & 111 & 287 & 100 \\
\hline
\end{tabular}

Simulium anamarie, $S$. riograndense e $S$. este tipo de substrato (Tabela 4). S. subpallidum subclavibranchium foram capturados apenas em e $S$. rubrithorax prevaleceram neste tipo de substrato rochoso. Embora a freqüência tenha sido substrato, indicando associação característica baixa, pode indicar preferência de colonização por com fundo rochoso do ribeirão, embora possam 
ser encontradas também em folhas soltas e na vegetação subaquática (Tabela 4). Folhas soltas no fundo dos ribeirões não foram o substrato mais colonizado pelas espécies. A ocorrência exclusiva de $S$. travassosi neste substrato foi evento único, o que impede qualquer discussão. Por outro lado, $S$. incrustatum, $S$. pertinax, $S$. inaequale e $S$. rubiginosum Enderlein, 1933 mostraram preferência em colonizar as partes submersas de plantas vivas, sendo $S$. dinelli exclusiva desse substrato (Tabela 4). Essas observações referem-se apenas às larvas e pupas identificadas. Outro fato que poderia alterar este cenário é a variação da composição específica em diferentes estações do ano.

Simulium incrustatum e $S$. pertinax são consideradas as espécies que causam maiores incômodos na população da região sudeste do Brasil, devido a sua intensa antropofilia e reações alérgicas provocadas por suas picadas (COSCARÓN, 1991). Assim como $S$. inaequale, elas foram as espécies mais constantes, sendo encontradas em todos os substratos e cursos de água (Tabelas 3 e 4). Peppinelli (2003) obteve exemplares de $S$. incrustatum aderidos à vegetação marginal em contato com a lamina de água e em restos vegetais (folhas) do leito, e Coscarón (1991) também relata esse hábito para a espécie. Figueiró et al. (2006) relatam que essa espécie está associada a pequenos criadouros de baixa vazão e pouco ensolarados, entretanto Santos (2008) a obteve em ambientes de dimensões maiores presentes em fitas plásticas introduzidas no riacho para pesquisa e no leito rochoso.

Simulium pertinax foi mais abundante no ribeirão João Pinheiro em áreas de maior correnteza e em substrato vegetal. Coscarón (1991) descreve que essa espécie desenvolve-se em rios de forte correnteza, apoiada em plantas ou ramos de vegetação tombados sobre o leito do rio, fatos que estão de acordo com o observado. Peppinelli (2003) coletou tal espécie em locais de diferentes dimensões, abertos com vegetação ripária, tanto em substratos vegetais quanto em leito rochoso. Strieder, Santos e Vieira (2006) relatam que $S$. pertinax prosperou nos arroios com maior poluição orgânica e degradação ambiental, salientandose, dessa maneira, a capacidade desta espécie em habitar diferentes ambientes.

Coscarón (1991) e Santos (2008) relatam que $S$. inaequale preferencialmente se desenvolve em córregos pequenos e rasos. Strieder (2002) acrescenta a preferência por córregos expostos à luz solar direta. Foi coletada em grande densidade em vertedouros e açudes por Peppinelli (2003). Dessa forma, verifica-se a grande valência ecológica na colonização de diferentes habitats por essas espécies, fato constatado também neste trabalho.

Simulium subnigrum foi coletada em todos os tipos de substrato apenas nos rios João Pinheiro e arroio Cascatinha, ou seja, apenas nas áreas sem degradação e com baixa intensidade solar, corroborando os resultados obtidos por Peppinelli (2003). Santos (2008) obteve a espécie em locais de dimensões maiores, tanto em áreas com maior quanto com menor incidência solar e com maior colonização de substratos artificiais como tubulação de concreto, indicando a adaptabilidade da espécie para ambientes modificados.

Foi coletada apenas uma larva de $S$. travassosi em folhas soltas no arroio Cascatinha, mas, segundo Strieder e Py-Daniel (1999), essa espécie se desenvolve em mananciais temporários com correnteza considerável, sobre substrato vegetal ou rochoso, expostos à luz solar direta. Peppinelli (2003) coletou a espécie em rio de dossel fechado, em restos vegetais e rochas, as mesmas características encontradas por Santos (2008).

Simulium riograndense, $S$. anamarie e $S$. subclavibranchium foram exclusivas de substrato rochoso e apresentaram baixa freqüência e abundância (Tabela 4). As condições físicas e químicas da água da região podem não ser o ideal às exigências reprodutivas das espécies. Peppinelli (2003) coletou $S$. riograndense aderidos ao substrato rochoso, em local de alta correnteza e sombreamento. O mesmo autor relata que $S$. 
anamarie apresenta hábito ainda desconhecido, encontrando a espécie aderida a seixos, principalmente em locais de forte correnteza, com vegetação ripária e intensidade luminosa moderada. Os dados obtidos para as três espécies, no Parque Ecológico da Klabin, assemelham-se aos resultados obtidos pelos autores acima citados. Segundo Strieder (2002), S. subclavibranchium possui ampla distribuição no Brasil. Coscarón (1991) relata que seu hábito e biologia ainda são incertos. Peppinelli (2003) coletou tal espécie em folha e galhos submersos, revelando também a sua presença sob o estrato vegetal. O registro de $S$. subclavibranchium em substrato rochoso acrescenta informação sobre sua ecologia.

Este é o primeiro registro de $S$. dinelli para o Estado do Paraná. Foram encontradas apenas duas larvas no ribeirão da Barragem aderidas à vegetação do leito. Segundo Peppinelli (2003), essa espécie tem ampla distribuição na América do Sul, e seus imaturos são encontrados em córregos de águas claras, podendo ainda estar presentes em vertentes termais. Peppinelli(2003) obteve imaturos aderidos à vegetação em um ribeirão que apresentava alteração antrópica e alta incidência solar, fato esse observado também neste estudo. Também é o primeiro relato de S. rubiginosum para o Estado do Paraná. Essa espécie foi coletada no arroio Cascatinha e no ribeirão da Barragem, apenas em substrato vegetal. A sua biologia é ainda incerta, e são poucos os trabalhos onde ela é citada. Wygodzinski (1971) comenta a existência desta espécie em áreas da Argentina e Colômbia, e sua ocorrência é relacionada ao ataque de rebanho de muares.

Os conhecimentos da distribuição local e a diversidade das formas imaturas de Simuliidae nos cursos de água são fundamentais para poder distinguir os padrões de abundância associados a eles, tanto em ambientes naturais quanto em locais onde há perturbações de origem antropogênica (STRIEDER; SANTOS; PÊS, 2002).

O Parque Ecológico da Klabin abriga uma fauna de simulídeos que apresenta distribuição espacial concordante com as características ecológicas préconcebidas, sendo ainda detentor de duas espécie ainda não registradas para o Estado. Nota-se que os levantamentos da fauna de simulídeos são essenciais tanto para conhecimento local quanto para orientação em futuras ações de controle destes dípteros, já que são hematófagos e potenciais vetores de patógenos.

\section{Agradecimentos}

Ao programa de Pós-Graduação em Ciências Biológicas da Universidade Estadual de Londrina, e à mestra Raquel B. dos Santos pela ajuda nas identificações. À CAPES pelo apoio financeiro.

\section{Referências}

BENNEMANN, S. T. A flora e a fauna do ribeirão Varanal: um estudo da biodiversidade no Paraná. Londrina: EDUEL, 2008.

COSCARÓN, S. Fauna de agua dulce de la República Argentina (Simuliidae Insecta, Diptera). Buenos Aires: FECIC, 1991.

COSCARÓN, S.; WYGODZINSKY, P. Notas sobre Simulidos neotropicales VII. Sobre los subgeneros Psaroniocompsa Enderlein y Inaequalium Subgen. Arquivos de Zoologia, São Paulo, v. 31, n. 2, p. 37-103, 1984.

CROSSKEY, R. W. First update to the taxonomic and geographical inventory of world blackflies (Diptera: Simuliidae). London: The Natural History Museum, 1990

CUNHA, M. C. I. Simulídeos (Borrachudos). In: MARCONDES, C. B. Entomologia médica e veterinária. São Paulo. Atheneu, 2001. p. 31-47.

CUNHA, M. C. I.; BASSI, R. M. A. Ensayo con Bacillus thuringiensis var. israelensis sobre simúlidos (Diptera, Simuliidae) en el río São João, Paraná, Brasil. Acta Biológica Paranaense, Curitiba, v. 26, n. 1/2/3/4, p. 9-21, 1997.

CUNHA, M. C. I.; COSCARÓN, S.; BASSI, R. M. A. Determinación de los estadios larvales de Simulium (Diptera, Simuliidae) de Paraná, Brasil. Acta Biológica Paranaense, Curitiba, v. 27, n. 1/2/3/4, p. 57-66, 1998. 
DELlOME FILHO, J. Simuliofauna do rio Marumbi (Morretes, Paraná, Brasil). I. Coleta e Criação; Dados Meteorológicos e Físico-químicos do Criadouro; Adultos (Diptera, Simuliidae). Acta Biológica Paranaense, Curitiba, v. 20, n. 1/2/3/4, p 145-156, 1991.

FIGUEIRÓ, R.; ARAÚJO-COUTINHO, C. J. P. C.; AZEVEDO, L. H. G.; NASCIMENTO, E. S.; MONTEIRO, R. F. Spatial and temporal distribution of blackflies (Diptera: Simuliidae) in the Itatiaia National Park, Brazil. Neotropical Entomology, Londrina, v. 35, n. 4, p. 542-550, Jul./Aug. 2006.

LOZOVEI, A. L.; CUNHA, M. C. I.; BASSI, R. M. A. Estudo das espécies de Simulídeos (Diptera, Simuliidae), que se procriam em vertedouros de açudes de piscicultura, Região Metropolitana de Curitiba, Paraná, Brasil. Anais da Sociedade Entomológica do Brasil, Jaboticabal, v. 3, p. 103-111, 1989.

LOZOVEI, A. L.; PETRI, F.; SANTOS NETO, L. G.; FERRAZ, M. E. Survey of the Simullium species (Diptera: Simuliidae), Riacho dos Padres, Almirante Tamandaré municipality, Paraná, Brasil. Revista Brasileira de Entomologia, São Paulo, v. 48, n. 1, p. 91-94, 2004.

PEPPINELLI, M. Diversidade de simuliidae (Diptera, Nematocera) em córregos do estado de São Paulo, Brasil. 2003. Dissertação (Mestrado em Ecologia e Recursos Naturais) - Universidade Federal de São Carlos, São Carlos.

PETRY, F. Aspectos biológicos de fertilidade e ciclo evolutivo de espécies de Simulium (Diptera, Simuliidae) e susceptibilidade de suas larvas em bioensaios laboratoriais com formulados de Bacillus thuringiensis israelensis em aparato elaborado. 2005. Dissertação (Programa de PósGraduação em Microbiologia, Parasitologia e Patologia) - Universidade Federal do Paraná, Curitiba.

PORTO ALEGRE. Secretaria Estadual da Saúde. Simulídeos: Programa Estadual - Rio Grande do Sul, Brasil: guia para orientação aos municípios sobre o manejo integrado, controle e gestão de insetos da família Simuliidae (Díptera; Nematocera) no Rio Grande do Sul. Porto Alegre: SEVS, 2006.

REIS, N. R; PERACCHI, A. L.; LIMA, I. P.; PEDRO, W. A. Riqueza de espécies de morcegos (Mammalia, Chiroptera) em dois diferentes habitats, na região centro-sul do Paraná, sul do Brasil. Revista Brasileira de Zoologia, Curitiba, v. 23, n. 3, p. 813-816, set. 2006.
SANTOS, R. B. Estudo da fauna de Simulídeos (Diptera: Simuliidae) do ribeirão Guaravera e afluentes, Distrito de Guaravera, Londrina, Paraná. 2008. Dissertação (Mestrado em Ciências Biológicas) - Universidade Estadual de Londrina, Londrina.

SANTOS-JUNIOR, J. E.; STRIEDER, M. N.; FIORENTIN, G. L.; NEISS, U. G. Velocidade da água e a distribuição de larvas e pupas de Chirostilbia pertinax (Kollar) (Diptera, Simuliidae) e macroinvertebrados associados. Revista Brasileira de Entomologia, São Paulo, v. 51, n. 1, p. 62-67, jan./mar. 2007.

STRIEDER, M. N. Diversidade e distribuição de Simuliidae (Diptera, Nematocera) no gradiente longitudinal da bacia do rio Maquiné, RS, Brasil. Biociências, Porto Alegre, v. 10, n. 1, p. 127-137, 2002.

Espécies de Simulídeos (Diptera, Nematocera, Simuliidae) no Rio Grande do Sul, Brasil: Distribuição Geográfica. Entomologia y Vectores, Salta, v. 11, n. 1, p. 113-143, 2004.

STRIEDER, M. N.; CORSEUIL, E.; PY-DANIEL, V. Espécies do gênero Simulium (Diptera, Simuliidae) ocorrentes no Rio Grande do Sul, Brasil, com chaves para sua identificação. Acta Biológica Leopoldensia, São Leopoldo, v. 14, n. 2, p 53-74, 1992.

STRIEDER, M. N.; PY-DANIEL, V. Espécies de Inaequalium (Diptera, Simuliidae): dados bionômicos e chaves para sua identificação. Biociências, Porto Alegre, v. 7, n. 2, p. 43-72, 1999.

STRIEDER, M. N.; SANTOS, J. E.; PÊS, A. M. O. Diversidade e distribuição de Simuliidae (Diptera, Nematocera) no gradiente longitudinal da bacia do rio dos Sinos, no Rio Grande do Sul, Brasil. Entomology y Vectores, Salta, v. 9, n. 4, p 527-540, 2002.

STRIEDER, M. N.; SANTOS, J. E.; VIEIRA, E. M. Distribuição, abundância e diversidade de Simuliidae (Diptera) em uma bacia hidrográfica impactada no sul do Brasil. Revista Brasileira de entomologia, São Paulo, v. 50, n. 1, p. 119-124, jan./mar. 2006.

WYGODZINSKI, P. Descriptions and redescriptions of species of the blackfly genus Simulium from the Northern Andes (Simuliidae, Diptera). New York: American Museum of Natural History, 1971.

Recebido em 3 de julho de 2008 - Received on July 3, 2008. Aceito em 31 de março de 2009 - Accepted on March 31, 2009. 